\section{Wei-Lung Tseng \\ Huan-Tsung Chang}

Department of Chemistry, National Taiwan University, Taipei, Taiwan

\title{
A new strategy for optimizing sensitivity, speed, and resolution in capillary electrophoretic separation of DNA
}

\begin{abstract}
DNA separations were performed in poly(ethylene oxide) (PEO) solutions prepared in $100 \mathrm{~mm}$ Tris-boric acid (TB) buffers using a capillary filled with TB buffers with concentrations up to $2.5 \mathrm{M}, \mathrm{pH}$ 10.0. The electroosmotic flow (EOF) increased with increasing the concentration of TB buffers till $1.5 \mathrm{M}$ as a result of decreasing PEO adsorption on the capillary wall. At high TB concentrations $(>1.5 \mathrm{M})$, the peaks corresponding to small DNA fragments (11 and 8 base pairs) became sharper and were detected. Relative standard deviations of the EOF coefficient and the migration times of the DNA fragments were all less than $1 \%$ using a capillary filled with TB buffers at concentrations higher than $1.5 \mathrm{~m}$. When separations were performed at different $\mathrm{pH}$ values of PEO solutions and TB buffers, better results in terms of sensitivity, speed, and resolution were generally achieved. The fluorescence intensity of the $2176 \mathrm{bp}$ fragment obtained at $\mathrm{pH}$ values of TB buffers/PEO solutions 10.0/8.2 was 27-fold of that at $\mathrm{pH}$ values 8.2/8.2. The enhancement was related to effects of $\mathrm{pH}$ and borate on fluorescence intensity, DNA conformation, stacking, and interactions with the capillary wall. Using a capillary filled with $400 \mathrm{~mm}$ TB buffers, $\mathrm{pH}$ 10.0, the separation of DNA (pBR 322/Haell digest, pBR $328 / B g / l$ digest and pBR $328 /$ Hinfl digest) in $1.5 \%$ PEO solutions prepared in $100 \mathrm{~mm}$ TB buffers, $\mathrm{pH} 9.0$, at $375 \mathrm{~V} / \mathrm{cm}$ was accomplished in less than $18 \mathrm{~min}$.
\end{abstract}

Keywords: Capillary electrophoresis / DNA / Polymer solutions / Electroosmotic flow

EL 4245

\section{Introduction}

The high resolving power and speed of capillary electrophoresis (CE) makes it an interesting tool for DNA separation [1-4]. Deactivated capillaries filled with entangled polymer solutions, such as linear polyacrylamide (LPA), agarose and PEO, are commonly used to provide highresolution and reproducible DNA separation [5-10]. To minimize interaction between DNA and the capillary wall, to suppress EOF and improve reproducibility, many attempts have been developed such as coating the capillary wall with polymer molecules [11-14]. These capillaries generally have a limited lifetime and are highly costly. To overcome these problems, capillaries dynamically coated with polymers dissolved in the running buffer have been introduced $[15,16]$.

Recently, we have turned our attention towards the separation of DNA in the presence of EOF using entangled polymer solutions $[17,18]$. PEO solutions entered capillaries by EOF during the separation and acted as sieving

Correspondence: Dr. Huan-Tsung Chang, Department of Chemistry, National Taiwan University, Taipei, Taiwan, R. O. C. E-mail: changht@mail.ch.ntu.edu.tw Fax: +011-886-2-23621963

Abbreviations: EB, ethidium bromide; EPM, electrophoretic mobility; PEO, poly(ethylene oxide); PEPM, pseudo-electrophoretic mobility matrices for high-resolution DNA separation. As DNA migrates against EOF, large DNA fragments are detected earlier than small ones. Because the differential migration mobility is smaller, resolution between two adjacent large DNA fragments is comparatively poor. After washing capillaries with $0.5 \mathrm{~m} \mathrm{NaOH}$ at $1 \mathrm{kV}$ for $10 \mathrm{~min}$, reproducible EOF mobility is generated ( $<3 \%$ relative standard deviation, RSD) and thus, any highly viscous polymer solutions and very small-size capillaries can be employed. In the presence of EOF, gradient or stepwise techniques can be performed for DNA analysis [19].

In DNA separation via this method it is important that resolution and speed can be further optimized by regulating EOF through control of charge and composition of the capillary wall [20]. Factors affecting EOF, such as $\mathrm{pH}$, ionic strength and composition of the running buffers, are considered in several studies [21-24]. It is thought that changes in EOF are related to continuous modification of the wall surface resulting from interactions with buffer components and solutes [25]. Thus, the magnitude of EOF changes is also time-dependent. For example, it generally takes more than one hour for EOF mobility to reach a constant value using a capillary treated with alkaline solutions and subsequently with running buffers [26].

In our previous studies, we have found that the decrease of EOF due to PEO adsorption on the capillary wall is significant [17-19]. It has long been considered that PEO 
adsorption occurs mainly by hydrogen bonding and hydrophobic interactions [27]. Thus, factors such as $\mathrm{pH}$ and ionic strength, affecting the properties of the capillary wall and PEO molecules, play crucial roles in determining EOF and thus resolution. These factors also influence DNA conformation and intercalation with dyes. With increasing $\mathrm{pH}$, the diffusion and electrophoretic mobility of DNA decrease due to changes in DNA conformation [28]. Consequently, the DNA band is sharp and thus, a separation efficiency of as high as $3 \times 10^{6}$ plates $/ \mathrm{m}$ has been achieved. In addition, effects of small molecules, such as borate or ethidium bromide (EB), in running buffers on the electrophoretic mobility (EPM) of DNA are related to resolution $[29,30]$. In this regard, there are several important questions to be addressed in this study: (i) How do $\mathrm{pH}$ and TB concentration affect EOF and resolution? (ii) Can PEO adsorption be minimized? (iii) Can reproducibility be improved?

Sensitivity is always an important issue in DNA analysis although methods allowing the detection of single molecules have been reported [31, 32]. DNA analysis via CE with laser-induced fluorescence (LIF) has been commonly carried out in buffers containing intercalators such as EB and thiazole green [33-35]. To optimize sensitivity, intercalators that form stable complexes with DNA (formation constant $\approx 10^{7}-10^{9}$ ) are required. Because the stability of complexes is related to the ratio of DNA and intercalators, $\mathrm{pH}$, ionic strength, and composition of buffers [3337], it is worthy evaluating effects of these factors on sensitivity in this study. In an attempt to answer the abovementioned questions, we performed DNA separations in $1.5 \%$ PEO solutions prepared in a variety of TB buffers using a capillary filled with different TB buffers. We also demonstrated DNA separations using a capillary filled with TB buffers at different $\mathrm{pH}$ values from those of PEO solutions. Sensitivity, speed, and resolution obtained from different conditions were carefully compared.

\section{Materials and methods}

\subsection{Equipment}

The basic design of the separation system has been previously described [17]. Briefly, a high-voltage power supply (Gamma High Voltage Research Inc., Ormond Beach, FL, USA) was used to perform electrophoresis. The entire detection system was enclosed in a black box with a highvoltage interlock. The high-voltage end of the separation system was put in a home-made plexiglass box for safety. A $4.0 \mathrm{~mW}$ He-Ne laser with $543.6 \mathrm{~nm}$ output from Uniphase (Mantence, CA, USA) was used for excitation. The light was collected with a $20 \times$ objective (numerical aperture 0.25 ). One RG 610 cutoff filter was used to block scattered light before the emitted light reaches the photo- tube (Hamamatsu R928). The amplified currents were transferred directly through a $10 \mathrm{k} \Omega$ resistor to a 24 bit $\mathrm{A} / \mathrm{D}$ interface at $10 \mathrm{~Hz}$ (Borwin ${ }^{\mathrm{TM}}$; JMBS Developments, Le Fontanil, France) and stored in a PC. Bare fused-silica capillaries (BIOTAQ.COM.Inc, Potomac, MD, USA) with $75 \mu \mathrm{m}$ ID and $365 \mu \mathrm{m}$ OD were used for DNA separations without any further coating process.

\subsection{Chemicals}

All chemicals for preparing buffer solutions were from Aldrich (Milwaukee, WI, USA). EB was obtained from Molecular Probes (Eugene, OR, USA). TB buffers were prepared from Tris adjusted by boric acid to $\mathrm{pH} 7.0,8.2,9.0$, and 10.0, respectively. Unless otherwise noted, $\times$ mM TB buffers means $\times \mathrm{mm}$ Tris solutions adjusted with a suitable amount of boric acid. PEO $\left(M_{\mathrm{r}} 8000000\right)$ solutions containing $5 \mu \mathrm{g} / \mathrm{mL}$ EB were dissolved in the TB buffers. DNA marker V (pBR 322/Haell digest) and VI (pBR 328/ Bgll digest and pBR 328/Hinfl digest) was purchased from Boehringer Mannheim (Mannheim, Germany).

\subsection{Preparation of PEO solutions}

Certain amounts of PEO were gradually added into the TB buffer solutions in a beaker, stirring in a water bath at $85-90^{\circ} \mathrm{C}$. During the addition of PEO, a magnetic stirring rod was used at high speed to produce a homogeneous solution. After addition was completed, the suspension was stirred for at least $1 \mathrm{~h}$. Finally, polymer solutions were degassed with a vacuum system in an ultrasonic tank. Polymer solutions stored in a refrigerator at $4^{\circ} \mathrm{C}$ could be used for at least a week.

\subsection{Separation and calculation}

Prior to analysis, capillaries were treated with $0.5 \mathrm{M} \mathrm{NaOH}$ overnight. After each run, capillaries were washed with $0.5 \mathrm{M} \mathrm{NaOH}$ at $1 \mathrm{kV}$ for 10 min to remove polymer solutions and refresh the capillary wall. Prior to injection of $1 \mu \mathrm{g} / \mathrm{mL}$ DNA samples by pressure at $30 \mathrm{~cm}$ for $5 \mathrm{~s}$, the capillary was filled with TB buffers. During the separation, PEO solutions entered the capillary by EOF and served as sieving matrices for DNA separations. The bulk EOF mobility was equal to $L / /(t V)$, where $L$ and $I$ are the total length $(\mathrm{cm})$ and effective length $(\mathrm{cm})$, respectively, $t$ is time (s), when the baseline shifted, and $V$ is the applied voltage (volt).

\section{Results and discussion}

\subsection{Effect of TB buffer concentrations on bulk EOF}

The bulk EOF decreased gradually as soon as more viscous PEO solutions entered the capillary filled with TB buffers $[17-19,38]$. In addition to viscosity dependence, 
PEO adsorption, leading to decreases in the zeta potential in the capillary wall, was taken into account for decreases in the bulk EOF. When using 1.5\% PEO solutions prepared in $100 \mathrm{~mm}$ TB buffers, $\mathrm{pH}$ 8.2, the EOF mobility increased with increasing the concentration of TB buffers, pH 10.0, filled in the capillary as shown in Fig. 1. The increase slowed down in the range of $1.5-2.5 \mathrm{M}$. The increasing tendency is different from the fact that EOF mobility decreases with increasing the ionic strength of electrolytes in the absence of polymers. Apparently, this is due to decreases in PEO adsorption at high concentrations of TB buffers. At high TB concentrations and $\mathrm{pH}$, the capillary surface was covered more completely with small molecules (Tris, borate, sodium, and hydroxide), leading to a more hydrophilic surface and a thinner double layer with a higher negatively charged density [39]. As a result, the hydrogen bonding and hydrophobic interaction between PEO molecules and the capillary wall were weakened.

To further support our suggestions, we need to calculate the bulk EOF mobility and the EPM values of DNA fragments. The time when the baseline shifted (not shown in the electropherograms) resulting from the detection of PEO matrices (neutral) was taken to calculate the bulk EOF mobility. When using the calculated bulk EOF to subtract migration mobility of DNA fragments, we could not obtain actual EPM values because the bulk EOF gradually decreased. Instead, we used pseudo-electrophoretic mobility (PEPM) of the DNA fragments to represent the calculated values in this study. The PEPM values for a certain DNA fragment obtained in different TB concentrations should be similar if PEO adsorption is not marked. The PEPM values for the 2176, 504 and 52 bp

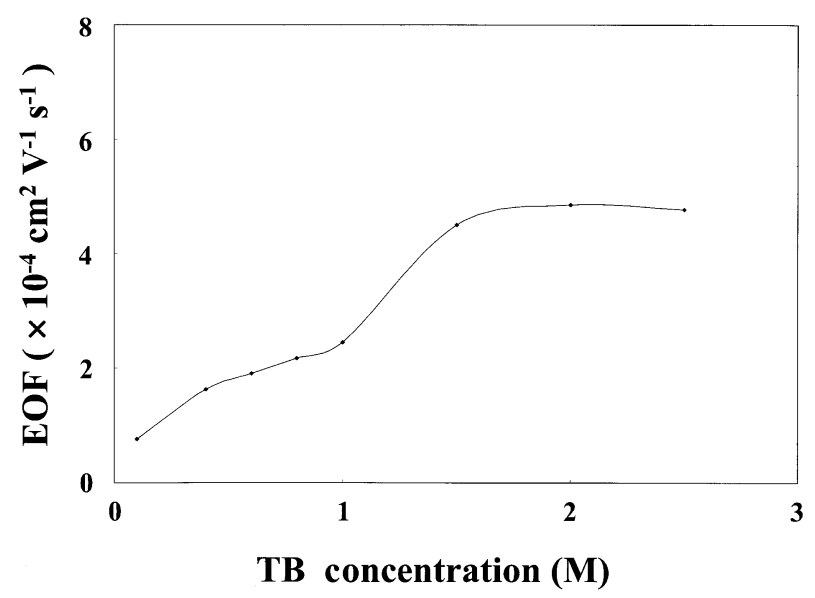

Figure 1. Effect of the concentration of TB buffers on the EOF in $1.5 \%$ PEO solutions containing $5 \mu \mathrm{g} / \mathrm{mL}$ EB at $15 \mathrm{kV}$. PEO solutions were prepared in $100 \mathrm{~mm}$ TB buffers, $\mathrm{pH}$ 8.2. Capillary, $40 \mathrm{~cm}$ total length, $30 \mathrm{~cm}$ effective length; filled with a variety of TB buffers, $\mathrm{pH} 10.0$. fragments were 0.07 and $0.66 \times 10^{-4} \mathrm{~cm}^{2} \mathrm{~V}^{-1} \mathrm{~s}^{-1}, 0.09$ and $0.75 \times 10^{-4} \mathrm{~cm}^{2} \mathrm{~V}^{-1} \mathrm{~s}^{-1}$, and 0.22 and $1.47 \times 10^{-4}$ $\mathrm{cm}^{2} \mathrm{~V}^{-1} \mathrm{~s}^{-1}$ when using a capillary filled with 100 and $1000 \mathrm{~mm}$ TB buffers, $\mathrm{pH}$ 10.0, respectively. As the bulk EOF mobility gradually decreased, it is not surprising that smaller PEPM values were obtained at low TB concentrations. It should be noted that PEPM values were also slightly related to borate concentration because of complexes formed between borate and DNA. In other words, if PEPM values varied only slightly with changing TB buffers, PEO adsorption is small. When using 1.5, 2.0 and $2.5 \mathrm{~m}$ TB buffers, the PEPM values of the $2176 \mathrm{bp}$ fragment calculated were 1.98, 2.19, and $2.18 \times 10^{-4} \mathrm{~cm}^{2}$ $\mathrm{V}^{-1} \mathrm{~s}^{-1}$, of the $504 \mathrm{bp}$ fragment were $2.17,2.39$, and $2.38 \times 10^{-4} \mathrm{~cm}^{2} \mathrm{~V}^{-1} \mathrm{~s}^{-1}$, and of the $52 \mathrm{bp}$ fragment were $3.46,3.73$, and $3.72 \times 10^{-4} \mathrm{~cm}^{2} \mathrm{~V}^{-1} \mathrm{~s}^{-1}$, respectively. These values were close to those obtained in the absence of EOF [40] and the results suggested that PEO adsorption was small at high TB concentrations. As a result of reduced adsorption of PEO and DNA, separations were highly reproducible. For instance, RSD values for the bulk EOF mobility and the migration time of the $51 \mathrm{bp}$ fragment were $<0.5 \%$, and $<1.0 \%$, respectively, using $2.0 \mathrm{~m} \mathrm{~TB}$ buffers, while using $100 \mathrm{~mm}$ TB buffers, we found 2.5 and $3.28 \%$, respectively.

\subsection{Effects of TB concentration}

Electropherograms shown in Fig. 2 demonstrate that eight peaks corresponding to DNA fragments with sizes ranging from 434 to $653 \mathrm{bp}$ were resolved in $1.5 \% \mathrm{PEO}$ solutions, $\mathrm{pH} 8.2$, using a capillary filled with (A) $400 \mathrm{~mm}$ and $(\mathrm{B}) 1 \mathrm{M}$ TB buffers, $\mathrm{pH} 10.0$, respectively. It is interesting to note that the migration times for larger DNA were longer using $400 \mathrm{~mm}$ TB buffers compared to those using $1 \mathrm{~m}$ TB buffers, while they were shorter for small DNA fragments. This is because the EPM of DNA (against EOF) increased with increasing borate concentrations. With greater EPM against a small bulk EOF, the migration times for small DNA fragments became longer. Please note that the bulk EOF obtained when the baseline shifted was higher than that when the small DNA fragments were detected and that the fluorescence intensity of 18 and $21 \mathrm{bp}$ fragments decreased with decreasing the TB concentration. Because the fluorescence intensity of intercalated DNA changed only slightly with varying TB concentration, it must be due to DNA interaction with the capillary wall, which is more marked for small DNA [41].

To optimize the sensitivity for small DNA fragments, especially for fragments $<51 \mathrm{bp}, 1.5 \mathrm{~m}$ TB buffers were used (not shown). Although the separation was faster (shorter than $17 \mathrm{~min}$ ), the above-mentioned eight peaks were not completely resolved. Because the migration times of the $18 \mathrm{bp}$ fragments, obtained by using $1 \mathrm{~m}$ TB 

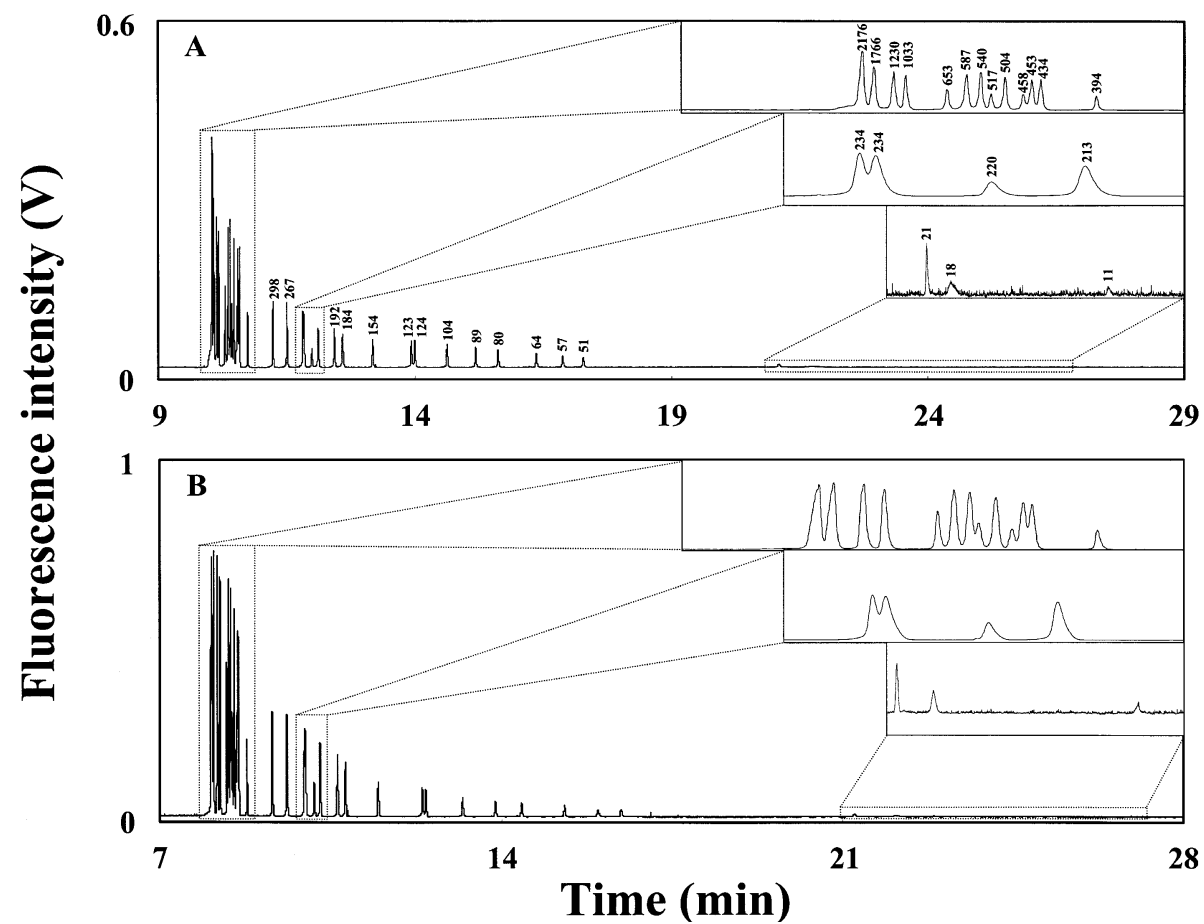

Figure 2. Separation of DNA markers $\mathrm{V}$ and $\mathrm{VI}$ in 1.5\% PEO solutions, prepared in $100 \mathrm{~mm}$ TB buffers, pH 8.2 , using a $40 \mathrm{~cm}$ capillary filled with $400 \mathrm{~mm}$ and $1 \mathrm{~m}$ TB buffers, $\mathrm{pH}$ 10.0, respectively, at $15 \mathrm{kV}$. buffers, was close to that using $1.5 \mathrm{M}$ TB buffers, we believe that loss of detecting the $11 \mathrm{bp}$ fragment (Fig. 2B) was not due to diffusion. These observations supported our reasoning that DNA interactions with the capillary wall were weakened at high TB concentrations. It is surprising that any two adjacent DNA fragments larger than $1033 \mathrm{bp}$ were not completely resolved when using TB buffers at concentrations lower than $400 \mathrm{~mm}$ (smaller EOF mobility), while they were separated at high TB concentrations. At high TB concentrations, DNA fragments migrated with higher EPM against EOF, leading to a higher differential migration mobility and better resolution. The borate dependence of resolution is clearly shown in Table 1 indicating that, in this respect, the use of TB buffers at concentrations in the range of $100-600 \mathrm{~mm}$ is suitable. To this end, the $\mathrm{pH}$ change in the interface between TB buffers and PEO solutions should also affect resolution as a result of possible changes in DNA conformation and the stability of intercalated complexes [28].

\subsection{Effect of TB buffers on fluorescence intensity}

Peaks corresponding to 8 to 21 bp fragments are shown in Fig. 3 when DNA separations were carried out in 1.5\% PEO solutions at different $\mathrm{pH}$ values, from $\mathrm{pH} 7.0$ to 10.0 , using a capillary filled with $100 \mathrm{~mm}$ TB buffers, $\mathrm{pH}$ 10.0. The smallest DNA fragment (8 bp) was only detected at $\mathrm{pH} 10.0$, whereas the $11 \mathrm{bp}$ fragment could not be detected at $\mathrm{pH}$ 7.0. This is because the fluorescence intensity of EB intercalated DNA increased with increasing $\mathrm{pH}$. For example, the ratio of fluorescence intensities for the $1 \mu \mathrm{g} / \mathrm{mL}$ DNA intercalated with $5 \mu \mathrm{g} / \mathrm{mL}$ EB in TB buffers at $\mathrm{pH}$ 7.0, 8.2, 9.0, and 10.0 was 1.0:1.01:1.04: 1.24 under static conditions (in the absence of an electric field). An additional reason was the fact that peaks corresponding to the 18 and 21 bp fragments became broader due to diffusion and interactions with the capillary wall at $\mathrm{pH} 7.0$ and 8.2. Although it is better, with respect to speed

Table 1. Effect of TB concentration on resolution in 1.5\% PEO solutions prepared in $100 \mathrm{~mm}$ TB buffers, pH 8.2

\begin{tabular}{|c|c|c|c|c|c|c|c|c|c|c|c|}
\hline \multirow{2}{*}{$\begin{array}{l}{[\mathrm{TB}]} \\
(\mathrm{mM})\end{array}$} & \multirow[t]{2}{*}{$t_{0}{ }^{a)}$} & \multicolumn{10}{|c|}{ Resolution } \\
\hline & & $2176 / 1766$ & $653 / 587$ & $587 / 540$ & $540 / 517$ & $517 / 504$ & $504 / 458$ & $458 / 453$ & $453 / 434$ & $234 / 234$ & $124 / 123$ \\
\hline 100 & 17.48 & 0.59 & 7.67 & 5.46 & 3.84 & 3.84 & 5.78 & 1.18 & 3.39 & 0.81 & 1.77 \\
\hline 400 & 8.18 & 2.16 & 5.46 & 3.07 & 2.36 & 3.98 & 4.01 & 1.89 & 2.01 & 0.92 & 2.41 \\
\hline 600 & 7.00 & 2.71 & 4.01 & 3.07 & 2.51 & 3.98 & 3.66 & 2.01 & 2.36 & 1.11 & 2.31 \\
\hline 800 & 6.14 & 2.06 & 1.92 & 2.07 & 1.26 & 2.11 & 2.14 & 1.52 & 1.35 & 0.54 & 1.50 \\
\hline 1000 & 5.44 & 2.06 & 2.16 & 2.48 & 1.77 & 2.48 & 2.16 & 1.38 & 1.18 & 0.72 & 1.61 \\
\hline
\end{tabular}

a) Time when the baseline shifted due to detection of PEO matrices 


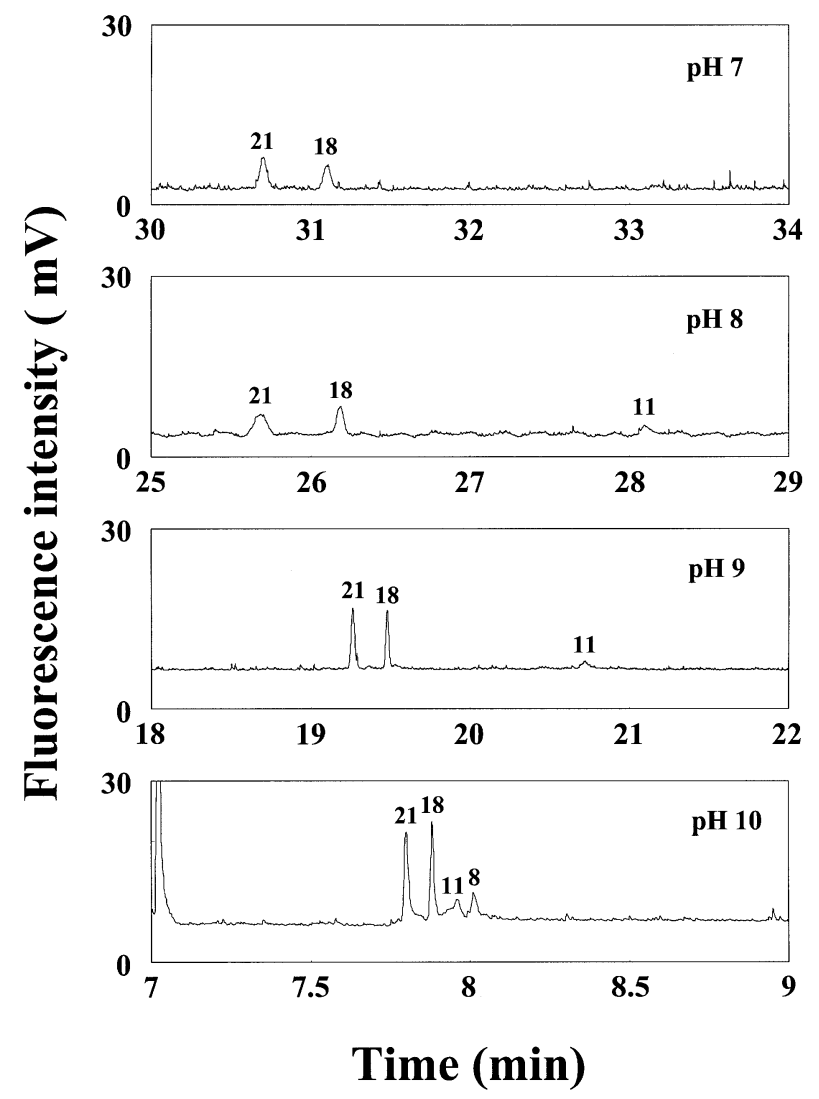

Figure 3. Effect of $\mathrm{pH}$ of $1.5 \%$ PEO solutions on separating small DNA fragments using a $40 \mathrm{~cm}$ capillary filled with $100 \mathrm{~mm}$ TB buffer, $\mathrm{pH}$ 10.0. Other conditions as in Fig. 2.

and sensitivity, for separating small DNA fragments at high $\mathrm{pH}$, the separation performed in PEO solutions above $\mathrm{pH} 10.0$ is not suggested because the large DNA fragments are not resolved and PEO solutions are not stable.

From the results shown above, the separation should be optimized under conditions when the $\mathrm{pH}$ values of $\mathrm{PEO}$ solutions and TB buffers are different. When two buffers at different $\mathrm{pH}$ values are used, the $\mathrm{pH}$ junction in the interface takes place and its magnitude depends on the buffer capacity of these two solutions. Thus, it is necessary to consider the effect of $\mathrm{pH}$ junction on separation performance [42, 43]. Figure 4 shows the ratios of the fluorescence intensities of the DNA fragments obtained in 1.5\% PEO solutions, pH 7.0 (A), $8.2(\mathrm{~B})$, and $9.0(\mathrm{C})$, respectively, using a capillary filled with $100 \mathrm{~mm}$ TB buffers, $\mathrm{pH}$ 10.0, to that filled with TB buffers, $\mathrm{pH} 7.0(\mathrm{~A}), 8.2(\mathrm{~B})$, and $9.0(C)$, respectively. Surprisingly, the fluorescence ratio was generally higher for the large DNA fragments. The ratios of the DNA fragments around $500 \mathrm{bp}$ were scattered because they were not completely resolved in

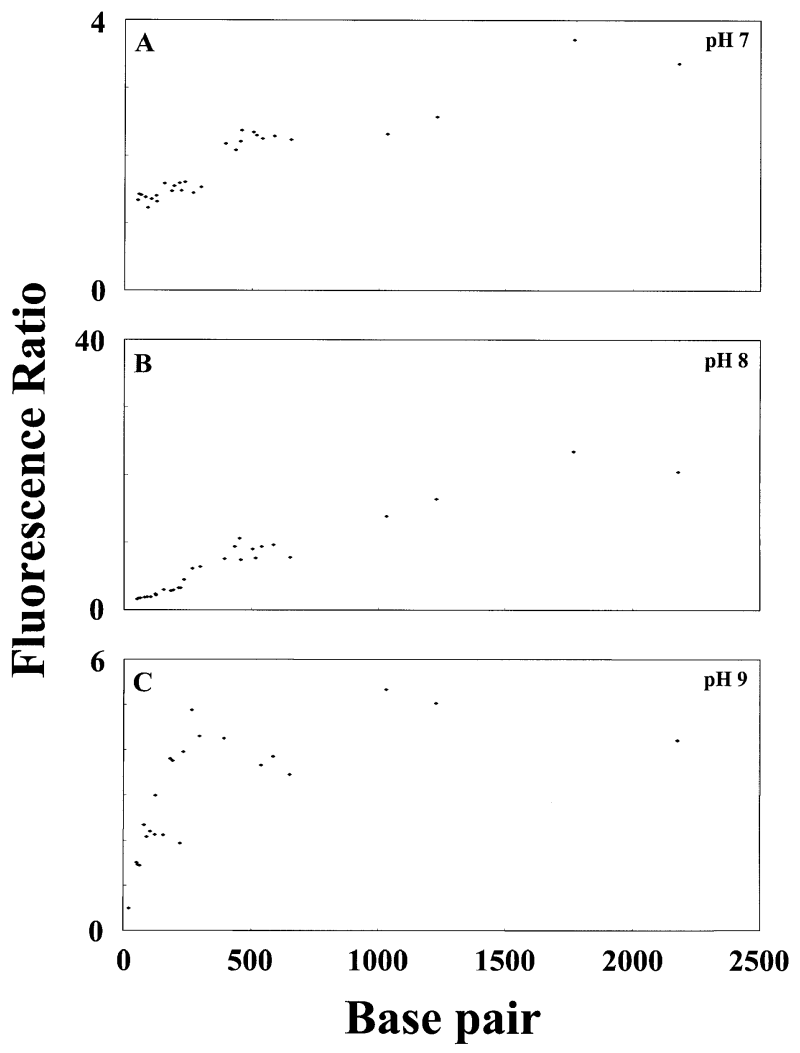

Figure 4. Comparison of the ratio of the fluorescence intensity of DNA fragments under different conditions. The fluorescence intensity was obtained at $\mathrm{pH}$ values of PEO solution/TB buffers $10.0 / 7.0$ to that obtained at (A) 7.0/7.0, (B) 10.0/8.2 to 8.2/8.2, and (C) 10/9.0 to 9.0/ 9.0 respectively. Other conditions as in Fig. 2 .

baseline. It is also interesting to note that the ratio shown in Fig. $4 \mathrm{~B}$ is higher than those in Figs. $4 \mathrm{~A}$ and $4 \mathrm{C}$. At $\mathrm{pH}$ 7.0 , although DNA stacked, the ratio is low because of small changes in $\mathrm{pH}$ near the interface between $\mathrm{PEO}$ solutions and TB buffers. At pH 9.0, DNA did not stack as effectively as that at $\mathrm{pH} 8.2$ because of a smaller difference in ionic strength between PEO solutions and TB buffers.

Figure 5 shows that the fluorescence intensity changed with varying concentration of TB buffers, $\mathrm{pH}$ 8.2. Overall, the fluorescence changes were not pronounced for small DNA fragments, while they were marked for larger DNA fragments. Under static conditions (in the absence of an electric field), the fluorescence intensity is almost TBindependent. Slight increases in the fluorescence intensity of small DNA fragments at high TB concentrations are probably because the interactions with the capillary wall were weakened. Because the large DNA fragment traversed near the interface between PEO solutions and TB buffers, the stacking efficiency decreased with in- 


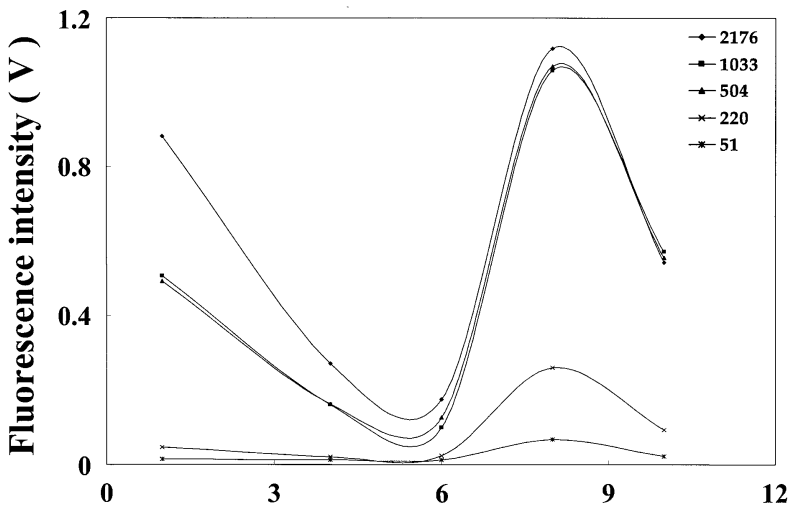

TB concentration $(\times 100 \mathrm{mM})$

Figure 5. Effect of TB concentration on the fluorescence intensity in 1.5\% PEO solutions prepared in $100 \mathrm{~mm}$ TB buffers, $\mathrm{pH} 8.2$, using a capillary filled with different TB buffers, $\mathrm{pH} 10.0$.

creasing TB concentrations ranging from 100 to $600 \mathrm{~mm}$. As the TB concentration was increased (600-800 mm), increases in $\mathrm{pH}$ must be one of the reasons for increasing the fluorescence intensity. In addition, weak interactions between the DNA fragments and the capillary wall and a minor diffusion due to shorter separation times should be attributed to higher fluorescence signals. As the concentrations of TB buffers were increased above $800 \mathrm{~mm}$, the fluorescence intensity decreased again. This is because DNA did not stack effectively at such high concentrations. A closer look at our results obtained under different conditions (not all shown) suggests that, in terms of sensitivity, the optimal concentrations of TB buffers are 1000, 800, and $400 \mathrm{~mm}$ when using 1.5\% PEO solutions, $\mathrm{pH} 7.0,8.2$, and 9.0 , respectively.

\subsection{Comparison of DNA separations under different conditions}

Figures $6 \mathrm{~A}-\mathrm{C}$ show DNA separations in 1.5\% PEO solutions prepared in $100 \mathrm{~mm}$ TB buffers, $\mathrm{pH} 9.0,8.2$, and 7.0 using a capillary filled with 400,800 , and $1000 \mathrm{~mm}$ TB buffers, pH 10.0, respectively. Two 234 bp DNA fragments and 123 and 124 bp fragments were separated. In terms of sensitivity, resolution, reproducibility, and speed, these results are much better than previous ones [19, 44]. At $\mathrm{pH}$ 9.0, the separation was accomplished in $18 \mathrm{~min}$. Because the fluorescence intensity is relatively low and the interaction with the capillary wall is comparatively strong at $\mathrm{pH} 7.0$, the $11 \mathrm{bp}$ fragment was not detected.

In order to carefully evaluate reasons for the changes in the fluorescence intensity under different conditions, the peaks corresponding to 1230,394 and 89 bp fragments
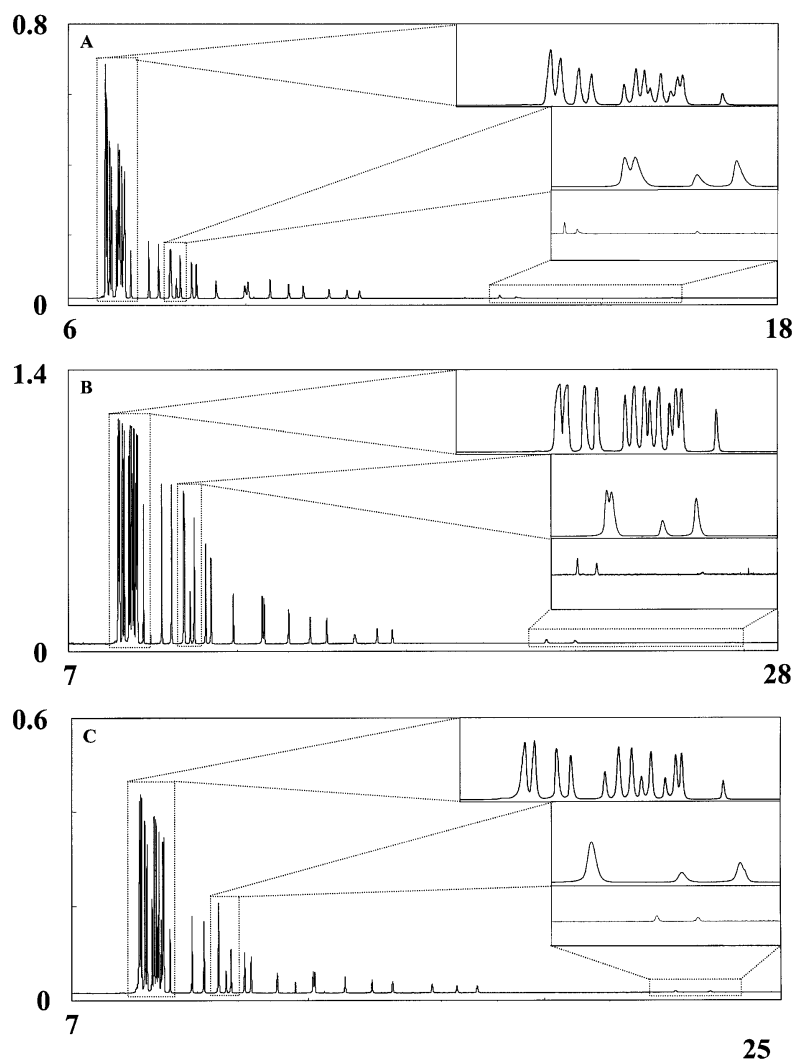

Time (min)

Figure 6. Separations of DNA fragments in 1.5\% PEO solutions prepared in $100 \mathrm{~mm}$ TB buffers, $\mathrm{pH} 7.0,8.2$, and 9.0 , using a capillary filled with $1 \mathrm{M}, 800 \mathrm{~mm}$, and $400 \mathrm{~mm}$ TB buffers, $\mathrm{pH} 10.0$, respectively. Other conditions as in Fig. 2.

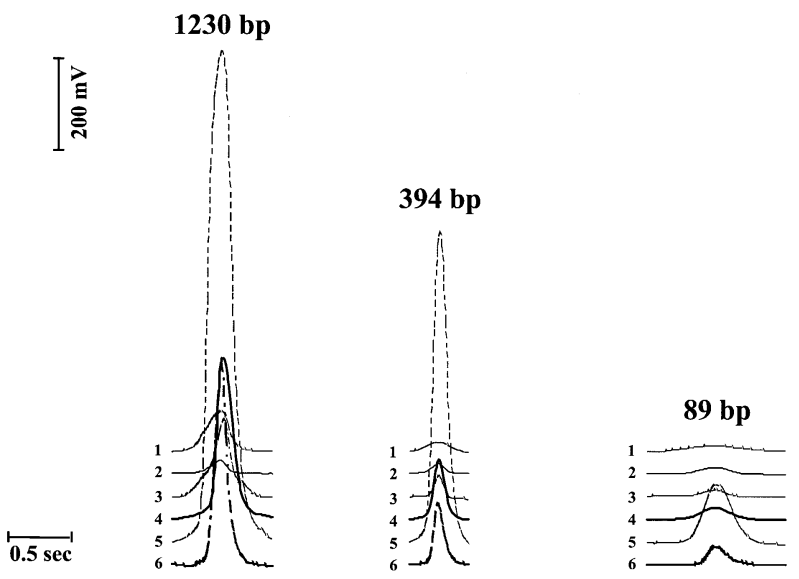

Figure 7. Comparison of the fluorescence intensity of three DNA fragments obtained under conditions given in Fig. 6. The fluorescence intensity was obtained at different $\mathrm{pH}$ values of TB buffers/PEO solutions: (1) 7.0/7.0, (2) $8.2 / 8.2$, (3) 9.0/9.0, (4) 10.0/7.0, (5) 10.0/8.2, (6) 10.0/ 9.0 . 
Table 2. Effect of $\mathrm{pH}$ of PEO solutions and $\mathrm{pH}$ and concentration and TB buffers on resolution, sensitivity, and system peak in DNA separation

\begin{tabular}{|c|c|c|c|c|c|c|c|c|c|}
\hline $\begin{array}{l}\mathrm{pH}^{\mathrm{a})} \\
(\mathrm{FS} / \mathrm{PS})\end{array}$ & $\begin{array}{l}\mathrm{FS} \\
(\mathrm{mm})\end{array}$ & $\begin{array}{l}t_{0}^{\mathrm{b})} \\
(\mathrm{min})\end{array}$ & & $\begin{array}{l}\text { Peak height } \\
(\mathrm{mV})\end{array}$ & & & Resolution & & $\begin{array}{l}\left.\text { Time window }{ }^{c}\right) \\
(\min )\end{array}$ \\
\hline & & & 2176 & 504 & 124 & 2176/1766 & $504 / 458$ & $124 / 123$ & \\
\hline $7 / 7$ & 100 & 4.54 & 98.25 & 57.82 & 21.25 & 4.03 & 1.89 & 2.21 & $7.36 \sim 23.13$ \\
\hline $10 / 7$ & 1000 & 6.43 & 396.71 & 150.40 & 42.35 & 2.16 & 2.87 & 1.05 & $8.73 \sim 17.29^{d)}$ \\
\hline $8.2 / 8.2$ & 100 & 4.29 & 41.02 & 56.10 & 22.49 & 2.44 & 1.67 & 2.22 & $6.65 \sim 16.10$ \\
\hline $10 / 8.2$ & 800 & 6.14 & 1117.38 & 1080.39 & 236.21 & 2.06 & 1.26 & 1.50 & $8.48 \sim 16.60^{\mathrm{e})}$ \\
\hline $9 / 9$ & 100 & 3.92 & 267.30 & 166.02 & 27.10 & 0.56 & 0 & 1.77 & $5.53 \sim 9.86$ \\
\hline $10 / 9$ & 400 & 5.13 & 659.43 & 371.24 & 34.795 & 1.77 & 1.65 & 1.22 & $6.63 \sim 10.93^{f)}$ \\
\hline
\end{tabular}

a) FS, TB buffers; PS, $1.5 \%$ PEO solutions prepared in $100 \mathrm{~mm}$ TB buffers

b) As shown in Table 1

c) Between migration times of the $2179 \mathrm{bp}$ and $51 \mathrm{bp}$ fragments

d) The last detected peak was the $18 \mathrm{bp}$ fragment $(23.19 \mathrm{~min})$

e) The last detected peak was the 11 bp fragment $(26.66 \mathrm{~min})$

f) The last detected peak was the $11 \mathrm{bp}$ fragment $(16.17 \mathrm{~min})$

were replotted regardless of the migration time in Fig. 7 . We conclude from the slight variations of the peak width that the decrease in the fluorescence intensity occurred not due to diffusion, but, most likely, resulted from a $\mathrm{pH}$ junction. Figure 7 also shows that the best conditions in terms of sensitivity were: $800 \mathrm{~mm}$ TB buffers, $\mathrm{pH} 10.0$, and $1.5 \%$ PEO solutions, $\mathrm{pH}$ 8.2. The plots also clearly show that the fluorescence intensity of the DNA fragments decreased in the order of the $\mathrm{pH}$ values of TB buffers/PEO solutions: 10.0/8.2 > 10.0/9.0 > 10.0/7.0 > 9.0/ $9.0>7.0 / 7.0 \approx 8.2 / 8.2$. Although the EOF mobility values were higher under conditions at $\mathrm{pH}$ values 7.0/7.0, 8.2/ 8.2, and 9.0/9.0, respectively, the DNA fragments $<51 \mathrm{bp}$ were not detected (Table 2). This is probably due to small fluorescence intensities of the DNA fragments and interactions with the capillary wall. It is important to note that the fluorescence intensity of the 2176 bp fragment obtained under the condition at $\mathrm{pH}$ values 10.0/8.2 showed a 27-fold enhancement of that obtained under the condition at $\mathrm{pH}$ values 8.2/8.2. Moreover, the resolution between any two DNA fragments ranging from 434 and 654 bp was further optimized, especially under the condition at $\mathrm{pH}$ values $10.0 / 7.0$. Finally, this method offers advantages over our previous method $[17,18]$ including better sensitivity, rapidity, optimal resolution, and reproducibility.

\section{Concluding remarks}

Controlling the $\mathrm{pH}$ and TB concentration is effective for EOF regulation and optimized resolution. As TB concentrations are increased, the separation is faster and reproducibility improves as a result of decreases in PEO and DNA adsorption. In terms of resolution, sensitivity, speed, and reproducibility, the optimal concentrations of TB buffers filled in the capillary are 400,800 , and $1000 \mathrm{~mm}, \mathrm{pH}$
10.0 , when separations were performed in $1.5 \%$ PEO solutions, $\mathrm{pH}$ 9.0, 8.2, and 7.0, respectively. The advantages of this new method over conventional CE methods (in the absence of EOF) include: (i) no need to fill capillaries with viscous polymer solutions prior to analysis, (ii) resolution and speed can be optimized by EOF regulation, (iii) sensitivity can be enhanced by $\mathrm{pH}$ and borate junction, (iv) it is more suitable for the analysis of PCR products because primers (small DNA fragments) migrate much slower, and ( $v$ ) gradient techniques can be applied to separations of DNA within a wide size range.

This work was supported by the National Science Council of the Republic of China under contract number NSC 892113-M002-035.

Received June 9, 2000

\section{References}

[1] Dolník, V., Novotny, M., J. Microcol. Sep. 1993, 4, 515-519.

[2] Fang, Y., Zhang, J. Z., Hou, J. Y., Lu, H., Dovichi, N. J., Electrophoresis 1996, 17, 1436-1442.

[3] Van der Schans, M. J., Kuypers, A. W. H. M., Kloosterman, A. D., Janssen, H. J. T., Everaerts, F. M., J. Chromatogr. A 1997, 772, 255-264.

[4] Mala, Z., Kleparnik, K., Boček, P., J. Chromatogr. A 1999, 853, 371-379.

[5] Carrilho, E., Ruiz-Martinez, M. C., Berka, J., Smirnov, I., Goetzinger, W., Miller, A. W., Brady, D., Karger, B. L., Anal. Chem. 1996, 68, 3305-3313.

[6] Liang, D., Song, L., Zhou, S., Zaitsev, V. S., Chu, B., Electrophoresis 1999, 20, 2856-2863.

[7] Chiari, M., Riva, S., Gelain, A., Vitale, A., Turati, E., J. Chromatogr. A 1997, 781, 347-355.

[8] Han, F., Huynh, B. H., Ma, Y., Lin, B., Anal. Chem. 1999, 71, 2385-2389. 
[9] Barron, A. E., Sunada, W. M., Blanch, H. W., Electrophoresis 1996, 17, 744-757.

[10] Boček, P., Chrambach, A., Electrophoresis 1991, 12, 1059-1061.

[11] Hjertén, S., J. Chromatogr. 1985, 347, 191-198.

[12] Cifuentes, A., Canalejas, P., Diez-Masa, J. C., J. Chromatogr. A 1999, 830, 423-438.

[13] Gelfi, C., Orsi, A., Leoncini, F., Righetti, P. G., J. Chromatogr. A 1995, 689, 97-105.

[14] Dolník, V., Xu, D., Yadav, A., Bashkin, J., Marsh, M., Tu, O., Mansfield, E., Vainer, M., Madabhushi, R., Barker, D., Harris, D., J. Microcol. Sep. 1998, 10, 175-184.

[15] Chiari, M., Cretich, M., Damin, F., Ceriotti, L., Consonni, R., Electrophoresis 2000, 21, 909-916.

[16] Kim, Y., Yeung, E. S., J. Chromatogr. A 1997, 781, 315-325.

[17] Chen, H.-S., Chang, H.-T., Electrophoresis 1998, 19, 3149-3153.

[18] Chen, H.-S., Chang, H.-T., Anal. Chem. 1999, 71, 2033-2036.

[19] Chen, H.-S., Chang, H.-T., J. Chromatogr. A 1999, 853, 337-347.

[20] Cohen, N., Grushka, E., J. Chromatogr. A 1994, 678, 167-175.

[21] Williams, B. A., Vigh, G., Anal. Chem. 1997, 69, 4445-4451.

[22] Knox, R. J., Burns, N. L., Van Alstine, J. M., Harris, J. M., Seaman, G. V. F., Anal. Chem. 1998, 70, 2268-2279.

[23] Stålberg, O., Ståhlberg, J., J. Chromatogr. A 1997, 776, 311-318.

[24] Graul, T. W., Schlenoff, J. B., Anal. Chem. 1999, 71, 4007-4013.

[25] Macka, M., Andersson, P., Haddad, P. R., Anal. Chem. 1998, 70, 743-749.

[26] Schwer, C., Kenndler, E., Anal. Chem. 1991, 63, 1801-1807.
[27] Mathur, S., Moudgil, B. M., J. Colloid Interface Sci. 1997, 196, 92-98.

[28] Liu, Y., Kuhr, W. G., Anal. Chem. 1999, 71, 1668-1673.

[29] Carmejane, O. D., Schwinefus, J. J., Wang, S. C., Morris, M. D., J. Chromatogr. A 1999, 849, 267-276.

[30] Carisson, C., Jonsson, M., Åkerman, B., Nucleic Acids Res. 1995, 23, 2413-2420.

[31] Taylor, J. R., Fang, M. M., Nie, S., Anal. Chem. 2000, 72, 1979-1986.

[32] Haab, B. B., Mathies, R. A., Appl. Spectrosc. 1997, 51, 1579-1584.

[33] Clark, S. M., Mathies, R. A., Anal. Chem. 1997, 69, 1355-1363.

[34] Owens, C. V., Davidson, Y. Y., Kar, S., Soper, S. A., Anal. Chem. 1997, 69, 1256-1261.

[35] Gelfi, C., Viganó, A., Curcio, M., Righetti, P. G., Righetti, S. C., Corna, E., Zunino, F., Electrophoresis 2000, 21, 785-791.

[36] Yan, X., Grace, W. K., Yoshida, T. M., Habbersett, R. C., Velappan, N., Jett, J. H., Keller, R. A., Marrone, B. L., Anal. Chem. 1999, 71, 5470-5480.

[37] Kim, Y., Morris, M. D., Anal. Chem. 1994, 66, 1168-1174.

[38] Chien, R. L., Helmer, J. C., Anal. Chem. 1991, 63, 1354-1361.

[39] Wallingford, R. A., Ewing, A. G., Adv. Chromatogr. 1989, 29, 1-73.

[40] Heller, C., Electrophoresis 1999, 20, 1962-1977.

[41] Iki, N., Kim, Y., Yeung, E. S., Anal. Chem. 1996, 68, 4321-4325.

[42] Xiong, Y., Park, S. R., Swerdlow, H., Anal. Chem. 1998, 70, 3605-3611.

[43] Britz-McKibbin, P., Chen, D. D. V., Anal. Chem. 2000, 72, 1242-1252.

[44] Chang, H.-T., Yeung, E. S., J. Chromatogr. B 1995, 669, 113-123. 